\title{
Epigallocatechin-3-gallate protects from high glucose induced podocyte apoptosis via suppressing endoplasmic reticulum stress
}

\author{
CHUNHONG XIANG ${ }^{*}$, XIAOYAN XIAO*, BEI JIANG, MENGKUN ZHOU, YIDAN ZHANG, HUI LI and ZHAO HU \\ Department of Nephrology, Qilu Hospital of Shandong University, Jinan, Shandong 250012, P.R. China
}

Received September 17, 2016; Accepted May 23, 2017

DOI: $10.3892 / \mathrm{mmr} .2017 .7388$

\begin{abstract}
Podocytes serve a critical role in the development of many glomerular diseases, including diabetic nephropathy (DN). Epigallocatechin-3-gallate (EGCG), a predominant polyphenolic component of green tea, has indicated its therapeutic effects in diabetes. In the present study, mouse podocyte cells were cultured in vitro, cell injury was induced by high glucose, and the protective effect of EGCG on cell proliferation and apoptosis and the underlying mechanisms were investigated. The results demonstrated that high glucose significantly inhibited cell proliferation after 48 and $72 \mathrm{~h}$ compared with normal glucose and mannitol treatment. EGCG (20 $\mu \mathrm{mol} / \mathrm{l})$ markedly promoted podocyte proliferation after 24, 48 and $72 \mathrm{~h}$ incubation with high glucose. Furthermore, high glucose significantly reduced WT-1 and nephrin expression in podocytes compared with the normal glucose and mannitol groups, while EGCG $(20 \mu \mathrm{mol} / \mathrm{l})$ treatment largely restored their expression. High glucose also significantly increased the apoptotic cell population compared with normal glucose and mannitol groups. However, EGCG combined with high glucose greatly decreased the apoptotic cell number compared with high glucose treatment alone. Furthermore, high glucose treatment was demonstrated to significantly increase glucose-regulated protein 78 (GRP78), phosphorylated- PKR-like ER kinase (p-PERK) and caspase-12 protein expression levels, which is representative of endoplasmic reticulum (ER) stress, compared with the normal glucose and mannitol groups. However, EGCG treatment significantly attenuated GRP78, p-PERK and caspase-12 protein expression induced by high glucose. These findings suggested that EGCG serves a protective role in glucose-induced podocyte apoptosis via suppressing ER stress, and may provide a novel therapeutic strategy to ameliorate the process of DN.
\end{abstract}

Correspondence to: Zhao Hu, Department of Nephrology, Qilu Hospital of Shandong University, 107 Wenhua Xi Road, Jinan, Shandong 250012, P.R. China

E-mail: hz12040813@163.com

${ }^{*}$ Contributed equally

Key words: epigallocatechin-3-gallate, podocyte, apoptosis, endoplasmic reticulum stress

\section{Introduction}

Diabetic nephropathy (DN) is one of most serious complications of both type 1 and type 2 diabetes, and frequently results in end-stage renal disease (ESRD), which eventually requires renal replacement therapy or renal transplantation (1). Initiation and development of DN is closely associated with podocyte injury and loss, and involved mechanisms include podocyte apoptosis, detachment, hypertrophy, effacement and loss of foot process proteins (2-5). Among them, podocyte apoptosis is a hotspot of research. Increasing data has that revealed endoplasmic reticulum (ER) stress serves an important role in the podocyte apoptosis $(6,7)$. It is understood that ER stress is a kind of adaptive response of the cell itself. Under normal physiological conditions, aggregated protein does not amass in cells partially due to the presence of cellular 'quality control' mechanisms (8). However, the unfolded protein response (UPR), whose role is restoring ER homeostasis and normal function, will activate a series of signaling molecules and induce the apoptosis cascade when the ER is exposed in a harmful environment for an extended period of time $(9,10)$. The UPR is characterized by the activation of three ER transmembrane effector proteins: PKR-like ER kinase (PERK), inositol requiring enzyme 1 (IRE1) and activating transcription factor-6 (ATF-6) (11). One major pathway of UPR is the suppression of most protein translations through phosphorylation of eukaryotic translation initiation factor 2 subunit a (eIf2a) by PERK (12). Another pathway is the upregulated expression of ER-localized molecular chaperones, such as glucose-regulated protein 78 (GRP78/Bip), GRP94 and other molecular chaperones like heat shock proteins (13). After a series of target protein activation, activation of ER resident protein caspase-12 will eventually lead to the cellular apoptosis (14).

Epigallocatechin-3-gallate (EGCG), the most abundant catechin in green tea, has been demonstrated to exert its anti-inflammatory, antioxidant and antitumor properties in chronic diseases including cancer $(15,16)$, neurodegenerative disease (17), diabetes (18), heart disease (19) and autoimmune arthritis (20). EGCG can prevent DN progression through decreasing reactive oxygen species (ROS) expression (21). However, the concrete mechanism of EGCG on high glucose-induced podocyte injury remains uncertain. The current study aimed to investigate the effects of EGCG on proliferation and apoptosis of mouse podocytes cultured in 
high glucose, and to provide a theoretical basis of the mechanisms involved in ER stress.

\section{Materials and methods}

Cell culture. The conditionally immortalized mouse podocytes donated by Dr Peter Mundel (Massachusetts General Hospital and Harvard Medical School, Charlestown, MA, USA) were maintained in RPMI1640 medium supplemented with $10 \%$ fetal bovine serum (Gibco; Thermo Fisher Scientific, Inc., Waltham, MA, USA), $10 \mathrm{U} / \mathrm{ml}$ interferon- $\gamma$ (PeproTech, Inc., Rocky Hill, NJ, USA) and $100 \mathrm{U} / \mathrm{ml}$ antibiotics (penicillin and streptomycin). Frozen podocytes were firstly cultivated at $33^{\circ} \mathrm{C}$ in a $5 \% \mathrm{CO}_{2}$ incubator. Then cells were cultured in medium at $37^{\circ} \mathrm{C}$ without interferon- $\gamma$ to induce differentiation for at least 2 weeks. Cells were cultured in serum-free medium for $24 \mathrm{~h}$ to synchronize the cell growth before each experiment.

Cell viability assay. Podocytes were seeded at a density of $1 \times 10^{\wedge} 4$ cells per well in 100 ul RPMI1640 complete medium on 96-well plates for $24 \mathrm{~h}$. Cells were divided into 10 groups as follows: $5.6 \mathrm{mM}$ D-glucose (group N), $5.5 \mathrm{mM}$ D-glucose and $24.5 \mathrm{mM}$ D-mannitol (group M), $30 \mathrm{mM}$ D-glucose (group H), $1 \mu \mathrm{M}$ EGCG (Sigma-Aldrich; Merck KGaA, Darmstadt, Germany) and $30 \mathrm{mM}$ D-glucose (group E1), $10 \mu \mathrm{M}$ EGCG and $30 \mathrm{mM}$ D-glucose (group E10), $20 \mu \mathrm{M}$ EGCG and $30 \mathrm{mM}$ D-glucose (group E20), $40 \mu \mathrm{M}$ EGCG and $30 \mathrm{mM}$ D-glucose (group E40), $60 \mu \mathrm{M}$ EGCG and $30 \mathrm{mM}$ D-glucose (group E60), $80 \mu \mathrm{M}$ EGCG and $30 \mathrm{mM}$ D-glucose (group E80), and $100 \mu \mathrm{M}$ EGCG and $30 \mathrm{mM}$ D-glucose (group E100). Cells were exposed to different conditions of reagents for 24, 48 or $72 \mathrm{~h}$. At each time point, cells were cultured with fresh medium with $10 \mu \mathrm{l}$ Cell Counting kit-8 (CCK-8; BD Biosciences, Franklin Lakes, NJ, USA) at $37^{\circ} \mathrm{C}$ for $3 \mathrm{~h}$. Cell proliferation was measured using a microplate reader (Model 680, Bio-Rad Laboratories, Hercules, CA, USA) at a wavelength of $450 \mathrm{~nm}$. Each individual experiment was repeated at least three times.

Podocyte injury and apoptosis. Cells of 4 groups (N, M, H and E20) in the above conditions were used for the following experiments. Mouse podocytes were inoculated at a density of $1 \times 10^{5}$ cells/well on cover slides in six-well plates. Then cells were washed with phosphate buffer saline (PBS) and incubated with $0.1 \%$ Triton X-100 at room temperature for $5 \mathrm{~min}$. Hoechst 33258 (Sigma-Aldrich; Merck KGaA) was added on the cells and incubated in the dark for $20 \mathrm{~min}$. Images were captured under a fluorescence microscope (Olympus DP72, Olympus Corporation, Tokyo, Japan).

Flow cytometry. Cells were selected for planting in the petri dishes with treatment of normal glucose, mannitol, high glucose or high glucose with $20 \mu \mathrm{mol} / 1 \mathrm{EGCG}$. Cells were collected after $72 \mathrm{~h}$ and the cell concentration was adjusted to $1 \times 10^{\wedge} 6$ in $500 \mu 1$ binding buffer (BD Biosciences). Annexin V-fluorescein isothiocyanate $(5 \mu \mathrm{l})$ and propidium iodide (PI; $10 \mu \mathrm{l}$ ) were added into each sample and incubated at $37^{\circ} \mathrm{C}$ for $30 \mathrm{~min}$ without bright light. The apoptosis data was acquired by a flow cytometer (Epics XL, Beckman Coulter, Inc., Kreefeld, Germany).
Western blotting. Cells were treated with different conditions and then lysed in radioimmunoprecipitation buffer containing protease inhibitor. After centrifugation at 24,000 x g and $4^{\circ} \mathrm{C}$ for $30 \mathrm{~min}$, supernatants were collected and analyzed for protein concentration with a Bicinchoninic Acid protein assay kit (Beyotime Institute of Biotechnology, Shanghai, China). Total protein (30-50 $\mu \mathrm{g})$ was diluted in sample buffer and boiled for $5 \mathrm{~min}$ for denaturation. Proteins in each sample were separated by $10 \%$ SDS-PAGE and transferred to a nitrocellulose filter membrane. After blocking with 5\% milk in PBS with Tween-20 for $1 \mathrm{~h}$, the membrane was incubated at $4^{\circ} \mathrm{C}$ overnight with the following primary antibodies: Anti-GAPDH (1:1,000; cat. no. ab9485), anti-Nephrin (1:1,000; cat. no. ab136894), anti-Wilms tumor protein 1 (WT-1; 1:1,000; cat. no. ab180840), anti-GRP78 (1:2,000; cat. no. ab21685), anti-caspase-12 (1:2,000; cat. no. ab62484) (all from Abcam, Cambridge, UK), anti-PERK (1:1,000; cat. no. sc-13073) and anti-phosphorylated (p)-PERK (1:1,000; cat.no.sc-32577)(both from Santa Cruz Biotechnology, Inc., Dallas, TX, USA). The membranes were washed and incubated with a goat anti-rabbit horseradish peroxidase-conjugated $\mathrm{IgG}$ secondary antibody (1:5,000; cat. no. ZB-2301, Origene Technologies, Inc., Rockville, MD, USA) at $24^{\circ} \mathrm{C}$ for $1 \mathrm{~h}$. Protein expression was detected with a chemiluminescence detection kit (EMD Millipore, Billerica, MA, USA). Data were analyzed using a western-blot analyzer (FluorChen E ProteinSimple Inc., San Jose, CA, USA).

Statistical analysis. All data are expressed as the mean \pm standard deviation. Data were analyzed using SPSS 18.0 software (SPSS Inc., Chicago, IL, USA). Data were analyzed by one-way analysis variance followed by Dunnett's multiple comparison test. $\mathrm{P}<0.05$ was considered to indicate a statistically significant difference.

\section{Results}

EGCG promotes podocyte proliferation. Cells were cultured with normal glucose (N), D-mannitol (M) and high glucose (H) for 24, 48 and $72 \mathrm{~h}$, respectively. CCK-8 reagent was used to detect podocyte proliferation. Optical density 450 values were used to represent cell proliferation. D-mannitol was used to observe the influence of hypertonicity on cells. As presented in Fig. 1A, there was no difference in cell proliferation among groups when cells were incubated for $24 \mathrm{~h}(\mathrm{P}>0.05)$. Cell proliferation in $\mathrm{H}$ group was significantly decreased compared with $\mathrm{N}$ and $\mathrm{M}$ groups when cells were incubated for 48 or $72 \mathrm{~h}(\mathrm{P}<0.05)$. There were no significant differences between $\mathrm{N}$ and $\mathrm{M}$ group. Interestingly, when EGCG with different concentrations was added to high glucose treated cells, EGCG especially at a concentration of $20 \mu \mathrm{mol} / 1$ (E20) significantly promoted cell proliferation $(\mathrm{P}<0.01$, Fig. $1 \mathrm{~B})$. However, its effect gradually decreased with increasing EGCG concentration (Fig. 1B).

EGCG attenuates high glucose-induced podocyte injury. WT-1 and nephrin are well-known podocyte-specific protein markers and thus are used to evaluate podocyte damage. It was demonstrated that both WT-1 and nephrin protein expression levels were decreased in podocytes 
A

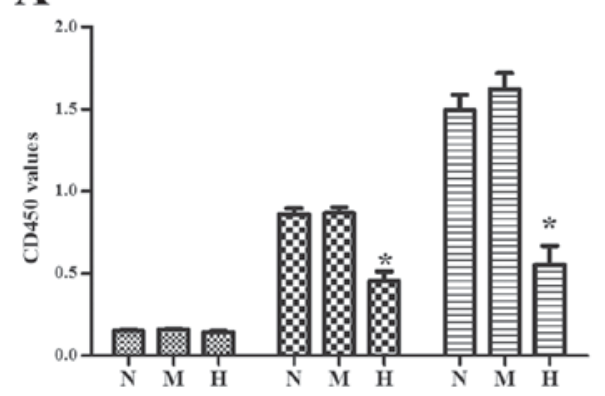

B

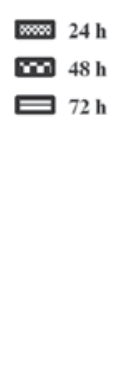

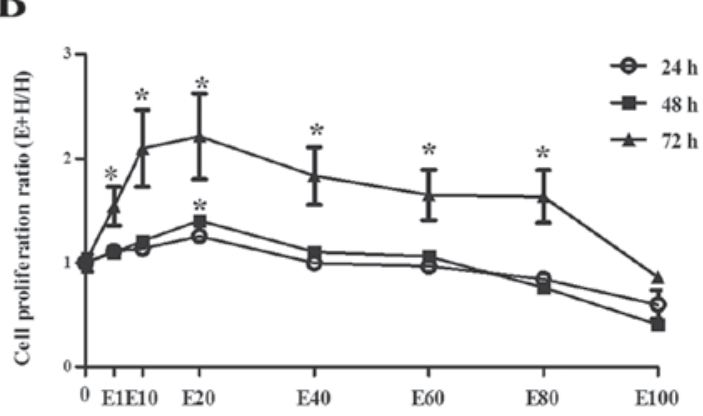

Figure 1. Podocytes were treated with varying concentrations of glucose and the cell proliferation was evaluated by Cell Counting kit- 8 assay. (A) The OD 450 values of different groups. (B) Cell proliferation ratio of different concentration gradient of EGCG group to high D-glucose group. Data are presented as the mean \pm standard deviation of at least three experiments in each group. "P $<0.05$ vs. N. N: $5.6 \mathrm{mM}$ D-glucose, M: $5.5 \mathrm{mM}$ D-glucose and $24.5 \mathrm{mM}$ D-mannitol, H: $30 \mathrm{mM}$ D-glucose. E1: $1 \mu \mathrm{M}$ EGCG and $30 \mathrm{mM}$ D-glucose, E10: $10 \mu \mathrm{M}$ EGCG and $30 \mathrm{mM}$ D-glucose, E20: $20 \mu \mathrm{M}$ EGCG and $30 \mathrm{mM}$ D-glucose, E40: $40 \mu \mathrm{M}$ EGCG and $30 \mathrm{mM}$ D-glucose, E60: $60 \mu \mathrm{M}$ EGCG and $30 \mathrm{mM}$ D-glucose, E80: $80 \mu \mathrm{M}$ EGCG and $30 \mathrm{mM}$ D-glucose, E100: $100 \mu \mathrm{M}$ EGCG and $30 \mathrm{mM}$ D-glucose. OD, optical density; EGCG, epigallocatechin-3-gallate.

WT-1

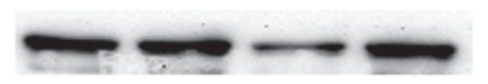

GAPDH
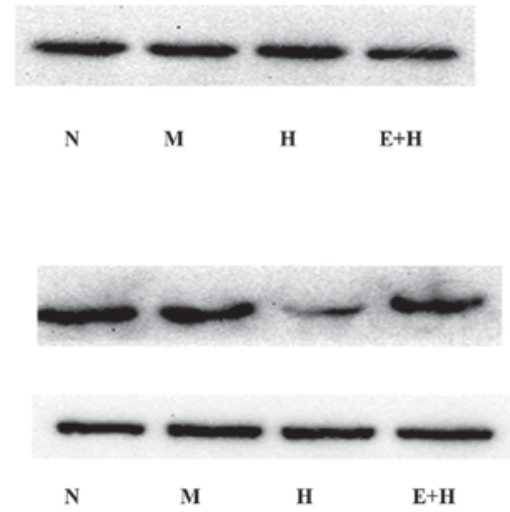
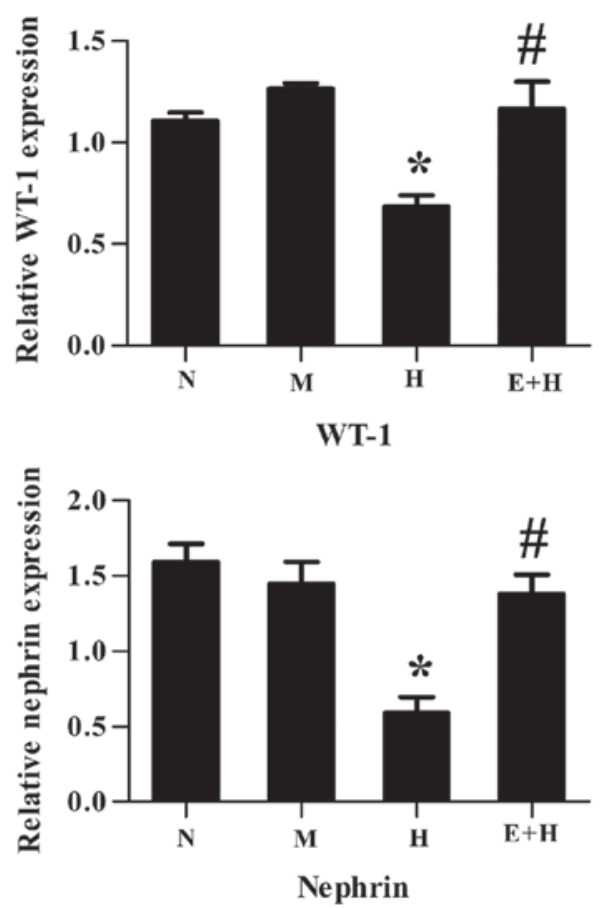

Figure 2. Western blot analysis of WT-1 and nephrin protein expression in different groups. Representative western blot images are presented. GAPDH served as an internal control. Data are presented as the mean \pm standard deviation of at least three experiments in each group. "P $<0.05$ vs. N; ${ }^{\sharp} \mathrm{P}<0.05 \mathrm{vs}$. H. N: $5.6 \mathrm{mM}$ D-glucose, M: 5.5 mM D-glucose and 24.5 mM D-mannitol, H: $30 \mathrm{mM}$ D-glucose, E+H: $20 \mu \mathrm{M}$ epigallocatechin-3-gallate and $30 \mathrm{mM}$ D-glucose. WT-1, Wilms tumor protein 1.

stimulated with high glucose compared with those with normal glucose or mannitol $(\mathrm{P}<0.05$, Fig. 2). However, this significantly increased following treatment of EGCG (20 $\mu \mathrm{mol} / \mathrm{l})$ and high glucose, compared with high glucose alone (P<0.05; Fig. 2).

EGCG reduces podocyte apoptosis induced by high glucose. Cells under different conditions were cultured for $72 \mathrm{~h}$ and cell apoptosis was analyzed by flow cytometry. There was little population of apoptotic cells in either the $\mathrm{N}(0.36 \%)$ and $\mathrm{M}(0.42 \%)$ groups, but the apoptotic population significantly increased in the high glucose group (7.1\%) compared with the normal and mannitol groups $(\mathrm{P}<0.05$, Fig. $3 \mathrm{~A})$. As predicted, EGCG $(20 \mu \mathrm{mol} / 1)$ treatment in high glucose incubated cells significantly reduced the apoptotic cell population percentage ( $3.24 \%$; $\mathrm{P}<0.05$; Fig. $3 \mathrm{~A}$ and $\mathrm{B})$.

In order to identify apoptotic cells, Hoechst 33258 was used for staining cell nuclear to detect cell apoptosis. In the $\mathrm{H}$ group, there were significantly more typical apoptotic cells, in which the nuclear shape became petals or nucleolus pyknosised, compared with the $\mathrm{N}$ and $\mathrm{M}$ groups (Fig. 3C). EGCG $(20 \mu \mathrm{mol} / \mathrm{l})$ greatly decreased the number of apoptotic cells treated with high glucose $(\mathrm{P}<0.05$; Fig. 3D).

EGCG attenuates GRP78, p-PERK and caspase-12 expression after high glucose stimulation. To investigate whether EGCG protects against high glucose-induced podocyte injury 
A

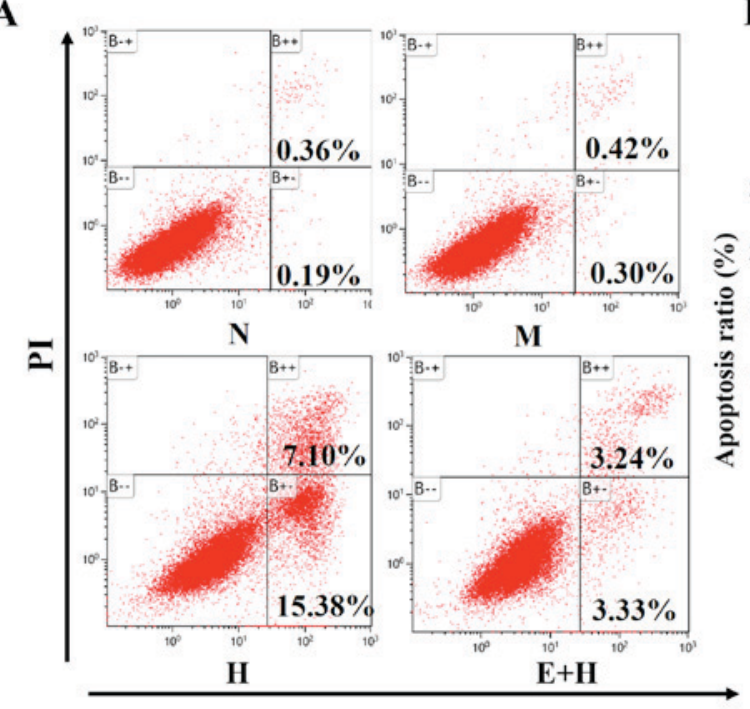

Annexin V

C
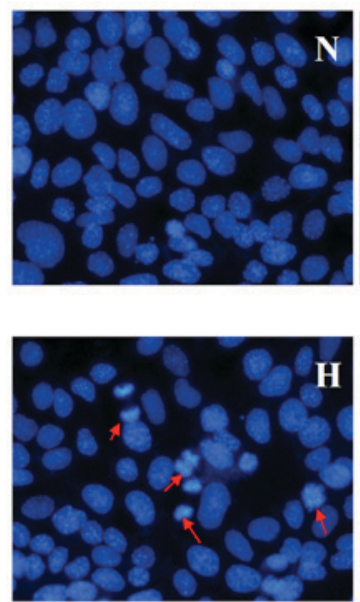
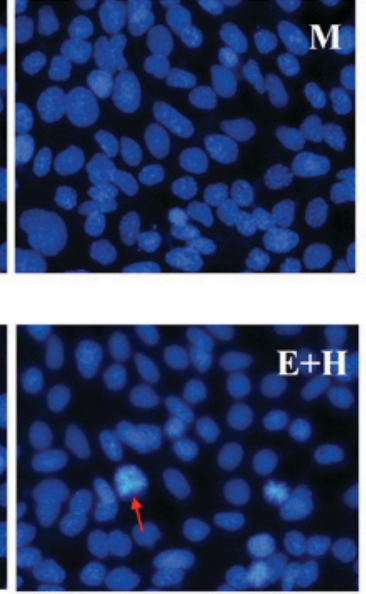

B

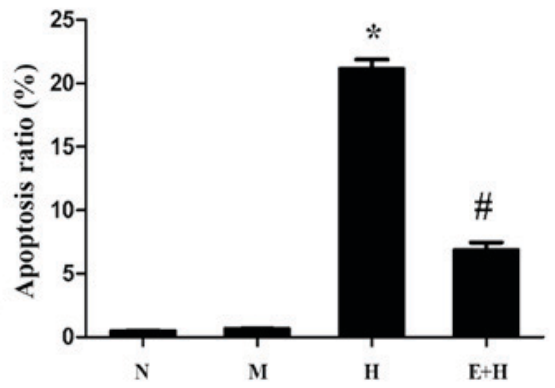

D

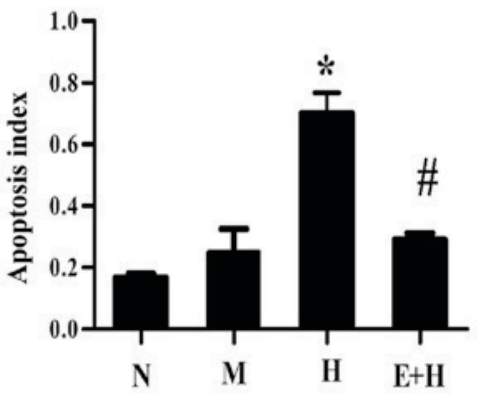

Figure 3. Apoptosis of podocytes. Representative flow cytometry (A) charts and (B) quantification of Annexin V and PI staining. (C) Fluorescence images of representative podocyte apoptosis, as assessed by Hochest 33258 staining. Arrows: apoptotic cell nuclei. Magnification, x400. (D) The apoptotic index was counted as the percentage of apoptotic cell nuclei per total nuclei number. Data are presented as the mean \pm standard deviation of at least three experiments in each group. ${ }^{*} \mathrm{P}<0.05$ vs. $\mathrm{N}$; ${ }^{\#} \mathrm{P}<0.05$ vs. H. N: $5 \mathrm{mM}$ D-glucose, M: $5.5 \mathrm{mM}$ D-glucose and $24.5 \mathrm{mM}$ D-mannitol, H: $30 \mathrm{mM}$ D-glucose, E+H, $20 \mu \mathrm{M}$ epigallocatechin-3-gallate and $30 \mathrm{mM}$ D-glucose. PI, propidium iodide.

via ER stress signaling, the expression of ER stress-associated markers, GRP78, p-PERK and caspase-12, were assessed. After high glucose stimulation, GRP78, p-PERK and caspase-12 were significantly increased compared with the normal glucose and mannitol groups ( $\mathrm{P}<0.05$; Fig. 4). However, these protein expression levels were markedly attenuated after EGCG $(20 \mu \mathrm{mol} / \mathrm{l})$ treatment $(\mathrm{P}<0.05$; Fig. 4).

\section{Discussion}

Podocytes are a type of highly differentiated and non-renewable glomerular epithelial cell (22). It is generally accepted that the loss and apoptosis of podocytes which occur at an early stage of DN are closely associated with its progression, and is a main cause of proteinuria and glomerulosclerosis development (23). Previous studies have demonstrated that EGCG treatment can attenuate ischemia/reperfusion-induced renal dysfunction though inhibition of proinflammatory cytokine cell apoptosis (24), and protect against cisplatin-induced nephrotoxicity via suppression of ER stress-induced (25) and mitochondrial dependent apoptotic pathways (26). The results of the present study demonstrated that EGCG is able to promote high-glucose induced podocyte proliferation and can also suppress high-glucose induced cell apoptosis of podocytes.

The ER serves an important role in adaptation of cell alterations under different conditions. It has been demonstrated that numerous factors, including free oxygen, immoderate nutrients, high glucose and free fatty acids, all can initiate apoptosis and generate ER stress and tissue damage (27). Podocyte loss in DN may be associated with ER stress-induced apoptosis $(28,29)$. High glucose can lead to cell injury and trigger ER stress in podocytes (28). GRP78, the first response protein and one of the main modulators of the UPR, has been generally implicated as a marker for the initiation of ER stress $(30,31)$. GRP78 combines with the $\mathrm{N}$-termini of transmembrane ER proteins to prevent protein 

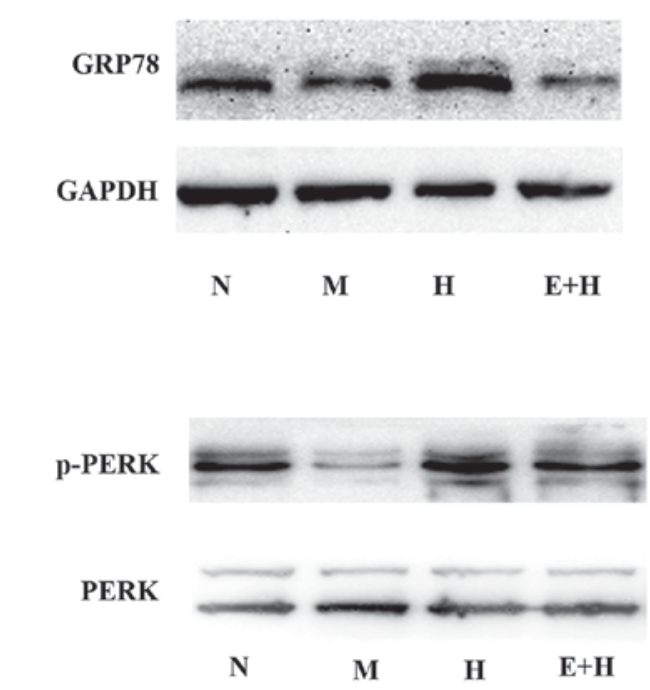

Caspase-12

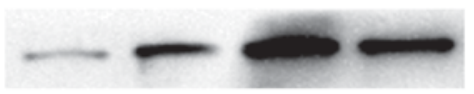

GAPDH

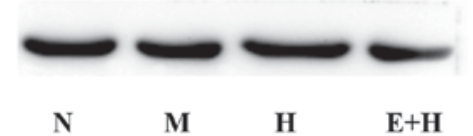

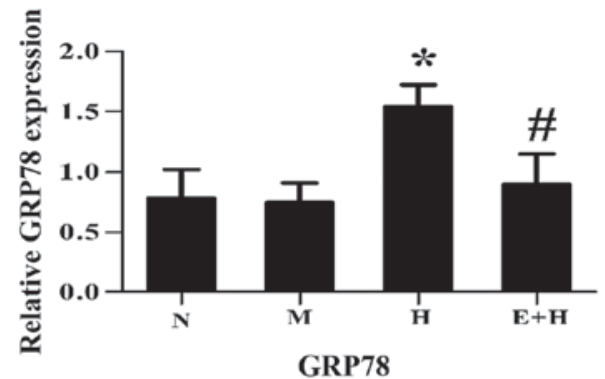
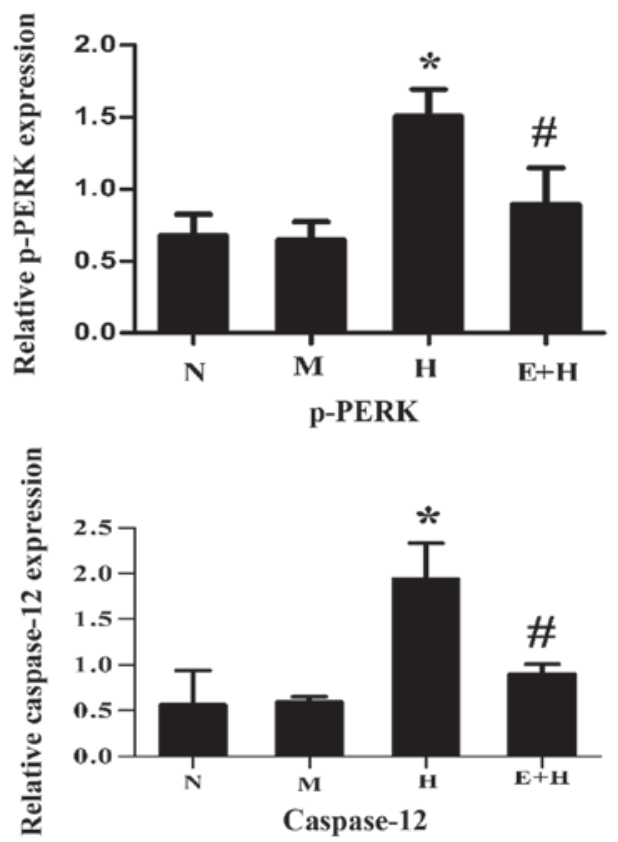

Figure 4. Western blot analysis of GRP78, p-PERK and caspase-12 protein expression levels in podocytes cultured in different groups. Representative western blot images and quantification of GRP78, p-PERK and caspase-12 relative to GAPDH are presented. Data are presented as the mean \pm standard deviation of at least three experiments in each group. ${ }^{*} \mathrm{P}<0.05$ vs. N; ${ }^{~} \mathrm{P}<0.05$ vs. H. N: $5 \mathrm{mM}$ D-glucose, M: $5.5 \mathrm{mM}$ D-glucose and $24.5 \mathrm{mM} \mathrm{D}$-mannitol, H: $30 \mathrm{mM} \mathrm{D}$-glucose, $\mathrm{E}+\mathrm{H}, 20 \mu \mathrm{M}$ epigallocatechin-3-gallate and $30 \mathrm{mM}$ D-glucose. p-PERK, phosphorylated PKR-like ER kinase; GRP78, glucose-regulated protein 78.

aggregation under normal conditions. When unfolded proteins amass, GRP78 is released and the vital transmembrane ER signaling proteins, including PERK, IRE1 and ATF6, are triggered to launch ER stress $(31,32)$. PERK cleaves from GRP78, inducing its autophosphorylation through oligomerization to further phosphorylate the $\alpha$ subunit of translation initiation factor 2 (eIF2 $\alpha$ ) to trigger ER stress (27). Thus, GRP78 serves a fundamental role in identification of unfolded proteins. Caspase-12, unlike other caspases, is specifically located in the cytoplasm of the ER and can be activated during ER stress but not through mitochondrial signals and other death stimuli (14). Upon caspase-12 activation, it can directly enter cytosol and process with downstream caspase family mainly including caspase-3, which leads to cell apoptosis (31). GRP78 is an inductor of ER stress and caspase-12 is an executor of ER stress-induced apoptosis. The current study indicates that ER stress is activated by high glucose, and protein expression of GRP78, p-PERK and caspase-12 are upregulated. EGCG treatment can reduce high glucose-induced ER stress. All the results suggest that EGCG may protect from podocyte apoptosis via suppression of ER stress pathway. A schematic representation of EGCG protection against podocyte apoptosis from high glucose stimulation, via ER stress signaling, is presented in Fig. 5.

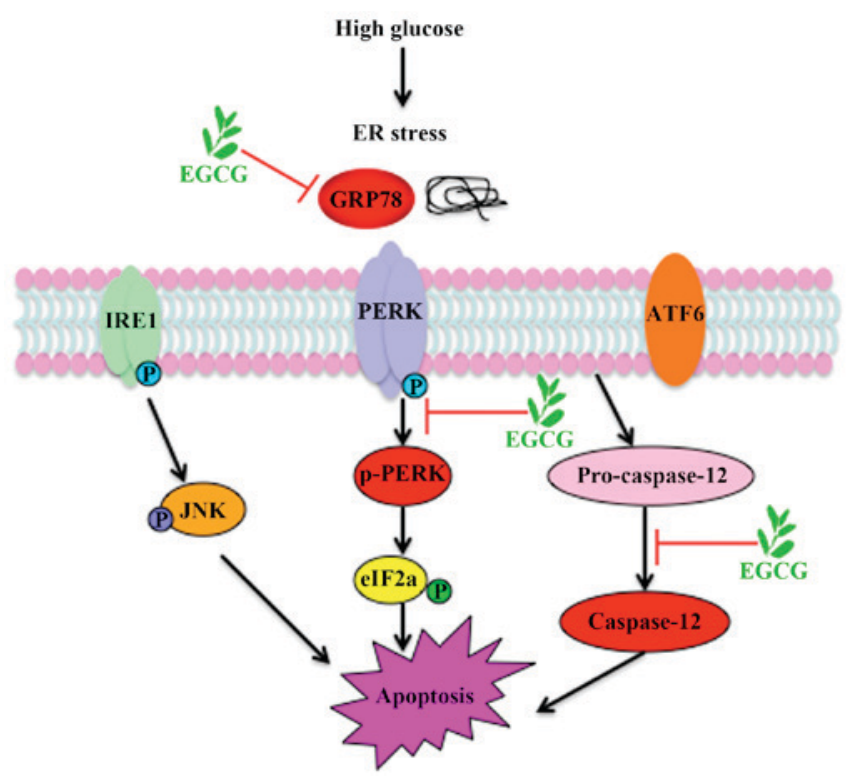

Figure 5. Hypothetical schematic of EGCG protection against podocyte apoptosis from high glucose stimulation through ER stress signaling. ER, endoplasmic reticulum; p, phosphorylated; JNK, c-Jun N-terminal kinase; EGCG, epigallocatechin-3-gallate; IRE1, inositol requiring enzyme 1; ATF-6, activating transcription factor-6; p-PERK, phosphorylated PKR-like ER kinase; eIf2a, eukaryotic translation initiation factor 2 subunit a. 
In conclusion, the present study demonstrated that EGCG promotes cell proliferation and apoptosis of high glucose-induced podocytes. Notably, EGCG was observed to suppress high glucose-induced ER stress-induced upregulation of GRP78, p-PERK and caspase-12 protein expression levels. Further study is required to clarify the efficacy of EGCG in the treatment of disease in vivo; however, the results of the present study indicated that it may have potential for the development of a therapeutic drug for DN.

\section{Acknowledgements}

The present study was supported by a General Financial Grant from the China Postdoctoral Science Foundation (grant no. 2015M572048), the Natural Science Fund of Shandong Province (grant no. ZR2013HM100 and ZR2014HM037) and the Science \& Technology Development Program of Shandong Province (grant no. 201401241).

\section{References}

1. Ilatovskaya DV, Levchenko V, Lowing A, Shuyskiy LS, Palygin O and Staruschenko A: Podocyte injury in diabetic nephropathy: Implications of angiotensin II-dependent activation of TRPC channels. Sci Rep 5: 17637, 2015.

2. Khazim K, Gorin Y, Cavaglieri RC, Abboud HE and Fanti P: The antioxidant silybin prevents high glucose-induced oxidative stress and podocyte injury in vitro and in vivo. Am J Physio Renal Physiol 305: F691-F700, 2013.

3. Ma J, Wu H, Zhao CY, Panchapakesan U, Pollock C and Chadban SJ: Requirement for TLR2 in the development of albuminuria, inflammation and fibrosis in experimental diabetic nephropathy. Int J Clin Exp Pathol 7: 481-495, 2014.

4. Liu BC, Song X, Lu XY, Li DT, Eaton DC, Shen BZ, Li XQ and Ma HP: High glucose induces podocyte apoptosis by stimulating TRPC6 via elevation of reactive oxygen species. Biochim Biophys Acta 1833: 1434-1442, 2013.

5. Brunskill EW, Georgas K, Rumballe B, Little MH and Potter SS: Defining the molecular character of the developing and adult kidney podocyte. PLoS one 6: e24640, 2011.

6. Cao AL, Wang L, Chen X, Wang YM, Guo HJ, Chu S, Liu C, Zhang XM and Peng W: Ursodeoxycholic acid and 4-phenylbutyrate prevent endoplasmic reticulum stress-induced podocyte apoptosis in diabetic nephropathy. Lab Invest 96: 610-622, 2016.

7. Madhusudhan T, Wang H, Dong W, Ghosh S, Bock F, Thangapandi VR, Ranjan S, Wolter J, Kohli S, Shahzad K, et al: Defective podocyte insulin signalling through $\mathrm{p} 85$-XBP1 promotes ATF6-dependent maladaptive ER-stress response in diabetic nephropathy. Nat Commun 6: 6496, 2015.

8. Brown MK and Naidoo N: The endoplasmic reticulum stress response in aging and age-related diseases. Front Physiol 3: 263, 2012.

9. Ron D and Walter P: Signal integration in the endoplasmic reticulum unfolded protein response. Nat Rev Mol Cell Biol 8: 519-529, 2007.

10. Luo B and Lee AS: The critical roles of endoplasmic reticulum chaperones and unfolded protein response in tumorigenesis and anticancer therapies. Oncogene 32: 805-818, 2013.

11. Okada T, Yoshida H, Akazawa R, Negishi M and Mori K Distinct roles of activating transcription factor 6 (ATF6) and double-stranded RNA-activated protein kinase-like endoplasmic reticulum kinase (PERK) in transcription during the mammalian unfolded protein response. Biochem J 366: 585-594, 2002.

12. Koumenis C, Naczki C, Koritzinsky M, Rastani S, Diehl A, Sonenberg N, Koromilas A and Wouters BG: Regulation of protein synthesis by hypoxia via activation of the endoplasmic reticulum kinase PERK and phosphorylation of the translation initiation factor eIF2alpha. Mol Cell Biol 22: 7405-7416, 2002.

13. Harding HP,Calfon M, Urano F, Novoa I and Ron D: Transcriptional and translational control in the Mammalian unfolded protein response. Annu Rev Cell Dev Biol 18: 575-599, 2002.
14. Nakagawa T, Zhu H, Morishima N, Li E, Xu J, Yankner BA and Yuan J: Caspase-12 mediates endoplasmic-reticulum-specific apoptosis and cytotoxicity by amyloid-beta. Nature 403: 98-103, 2000 .

15. Nowakowska A and Tarasiuk J: Comparative effects of selected plant polyphenols, gallic acid and epigallocatechin gallate, on matrix metalloproteinases activity in multidrug resistant MCF7/DOX breast cancer cells. Acta Biochim Pol 63: 571-577, 2016.

16. Granja A, Pinheiro M and Reis S: Epigallocatechin gallate nanodelivery systems for cancer therapy. Nutrients 8: pii: E307, 2016.

17. Ortiz-López L, Márquez-Valadez B, Gómez-Sánchez A, Silva-LuceroMD, Torres-PérezM, Téllez-Ballesteros RI,IchwanM, Meraz-Ríos MA, Kempermann G and Ramírez-Rodríguez GB: Green tea compound epigallo-catechin-3-gallate (EGCG) increases neuronal survival in adult hippocampal neurogenesis in vivo and in vitro. Neuroscience 322: 208-220, 2016.

18. Huang SM, Chang YH, Chao YC, Lin JA, Wu CH, Lai CY, Chan KC, Tseng ST and Yen GC: EGCG-rich green tea extract stimulates sRAGE secretion to inhibit S100A12-RAGE axis through ADAM10-mediated ectodomain shedding of extracellular RAGE in type 2 diabetes. Mol Nutr Food Res 57: 2264-2268, 2013.

19. Kim SJ, Li M, Jeong CW, Bae HB, Kwak SH, Lee SH, Lee HJ, Heo BH, Yook KB and Yoo KY: Epigallocatechin-3-gallate, a green tea catechin, protects the heart against regional ischemia-reperfusion injuries through activation of RISK survival pathways in rats. Arch Pharm Res 37: 1079-1085, 2014.

20. Yang EJ, Lee J, Lee SY, Kim EK, Moon YM, Jung YO, Park SH and Cho ML: EGCG attenuates autoimmune arthritis by inhibition of STAT3 and HIF-1alpha with Th17/Treg control. PLoS One 9: e86062, 2014.

21. Leu JG, Lin CY, Jian JH, Shih CY and Liang YJ: Epigallocatechin-3-gallate combined with alpha lipoic acid attenuates high glucose-induced receptor for advanced glycation end products (RAGE) expression in human embryonic kidney cells. An Acad Bras Cienc 85: 745-752, 2013.

22. Mundel P and Shankland SJ: Podocyte biology and response to injury. J Am Soc Nephrol 13: 3005-3015, 2002.

23. Butt A and Riaz S: Study of protein profiling of human urine in diabetic hypertensive nephropathy versus normal healthy controls. Diabetes Technol Ther 12: 379-386, 2010.

24. Lv J, Feng M, Zhang L, Wan X, Zeng YC, Liang PF and Xu AP: Protective effect of epigallocatechin gallate, a major constituent of green tea, against renal ischemia-reperfusion injury in rats. Int Urol Nephrol 47: 1429-1435, 2015.

25. Chen B, Liu G, Zou P, Li X, Hao Q, Jiang B, Yang X and Hu Z: Epigallocatechin-3-gallate protects against cisplatin-induced nephrotoxicity by inhibiting endoplasmic reticulum stress-induced apoptosis. Exp Biol Med (Maywood) 240: 1513-1519, 2015.

26. Zou P, Song J, Jiang B, Pei F, Chen B, Yang X, Liu G and Hu Z: Epigallocatechin-3-gallate protects against cisplatin nephrotoxicity by inhibiting the apoptosis in mouse. Int J Clin Exp Pathol 7: 4607-4616, 2014.

27. Ozcan U, Cao Q, Yilmaz E, Lee AH, Iwakoshi NN, Ozdelen E, Tuncman G, Görgün C, Glimcher LH and Hotamisligil GS: Endoplasmic reticulum stress links obesity, insulin action and type 2 diabetes. Science 306: 457-461, 2004.

28. Cao Y, Hao Y, Li H, Liu Q, Gao F, Liu W and Duan H: Role of endoplasmic reticulum stress in apoptosis of differentiated mouse podocytes induced by high glucose. Int J Mol Med 33: 809-816, 2014

29. Sun XY, Qin HJ, Zhang Z, Xu Y, Yang XC, Zhao DM, Li XN and Sun LK: Valproate attenuates diabetic nephropathy through inhibition of endoplasmic reticulum stressinduced apoptosis. Mol Med Rep 13: 661-668, 2016.

30. Groenendyk J, Sreenivasaiah PK, Kim DH, Agellon LB and Michalak M: Biology of endoplasmic reticulum stress in the heart. Circ Res 107: 1185-1197, 2010.

31. Xu C, Bailly-Maitre B and Reed JC: Endoplasmic reticulum stress: Cell life and death decisions. J Clin Invest 115: 2656-2664, 2005.

32. Schroder M and Kaufman RJ: ER stress and the unfolded protein response. Mutat Res 569: 29-63, 2005. 